\title{
Relationship between Tropical and Extratropical Diabatic Heating and Their Impact on Stationary-Transient Wave Interference 0
}

\author{
MingYu PARK AND SUKYOUNG LEe \\ Department of Meteorology and Atmospheric Science, The Pennsylvania State University, University Park, Pennsylvania
}

(Manuscript received 20 December 2018, in final form 13 May 2019)

\begin{abstract}
During boreal winter, the climatological stationary wave plays a key role in the poleward transport of heat in mid- and high latitudes. Latent heating is an important driver of boreal-winter stationary waves. In this study, the temporal relationship between tropical and extratropical heating and transient-stationary wave interference is investigated by performing observational data analyses and idealized model experiments. In line with stationary wave theory, the observed heating anomaly fields during constructive interference events have a spatial structure that reinforces the zonal asymmetry of the climatological heating field. The observational analysis shows that about 10 days prior to constructive interference events, tropical heating anomalies are established, and within 1 week North Pacific and then North Atlantic heating anomalies follow. This result suggests that constructive interference involves a heating-circulation relay: tropical latent heating drives circulation anomalies that transport moisture in such a manner as to increase latent heating in the North Pacific; circulation anomalies driven by this North Pacific heating similarly lead to enhanced latent heating in the North Atlantic. This heating-circulation relay picture is supported by initial-value model calculations in which the observed heating anomalies are used to drive model circulations. Our results also show that the constructive interference driven by both tropical and extratropical diabatic heating generates a relatively large-amplitude wave in high latitudes and leads to particularly prolonged Arctic warming episodes, whereas when both the tropical and extratropical diabatic heating are weak, constructive interference is confined to midlatitudes and does not lead to Arctic warming.
\end{abstract}

\section{Introduction}

The planetary-scale stationary wave plays an important role for regulating weather and climate in the Northern Hemisphere extratropics during the winter. Constructive interference with transient waves accentuates the effect of the stationary wave. In particular, it has been shown that stationary-transient wave constructive interference plays an important role in the extratropical response to tropical forcing (Fletcher and Kushner 2011; Smith et al. 2011; Garfinkel et al. 2012; Goss et al. 2016, hereafter GFL). It has been proposed that constructive interference is also likely to play a crucial role in maintaining equable climate conditions (i.e., where the equator-to-pole temperature gradient is relatively weak) even during winter (Lee 2012, 2014).

Supplemental information related to this paper is available at the Journals Online website: https://doi.org/10.1175/JAS-D-18-0371.s1.

Corresponding author: Mingyu Park,mup65@psu.edu
The basis of this equable climate theory is that the stationary wave is a major contributor to the poleward energy flux in mid- to high latitudes during boreal winter (Peixoto and Oort 1992); zonal asymmetry in the climatological tropical latent heating, while independent of the equatorto-pole temperature gradient, is important for forcing the stationary wave (Hoskins and Karoly 1981; Ting and Held 1990; Ting 1996; Held et al. 2002; Chang 2009); and there is a large untapped reservoir of zonal available potential energy (Lorenz 1955), which in principle can be unleashed by disturbances from outside of the extratropical baroclinic zone, such as the tropics (Lee 2014).

GFL hypothesized that constructive interference would be preceded by tropical heating anomalies that reinforce the climatological zonal asymmetry, and that it would be followed by anomalous warming in high latitudes. To test this hypothesis, GFL constructed an index, referred to as

Publisher's Note: This article was revised on 20 August 2019 to correct an error in a citation in section $2 \mathrm{a}$. 
the stationary wave index (SWI), which is positive (negative) for constructive (destructive) interference that measures the degree to which the instantaneous daily $300-\mathrm{hPa}$ streamfunction field matches with its winter climatology. It was found that the SWI tends to be positive 7-10 days after an enhanced warm pool convection, which enhances the zonal asymmetry of the climatological heating field in the tropics. Positive SWI days are typically followed by Arctic warming 8-10 days later. Examining the stationary wave responses to individual forcing terms, presented by Held et al. (2002), we find that the responses to diabatic heating fields-tropical and extratropical heating individuallyexhibit circulation patterns that promote warmth in the Arctic. Specifically, the wave solutions are composed of a southerly flow over the Bering Strait and Greenland and Norwegian Seas where most of the warm, moist air intrusions occur (Woods et al. 2013; Baggett et al. 2016; Woods and Caballero 2016). The southerly flow is especially prominent in the response to the extratropical heating.

Extratropical heating and tropical heating are unlikely to be independent of each other, however. The results of Baggett et al. (2016) raise the possibility that tropical heating leads to Arctic warming not just by its direct excitation of poleward and upward propagating planetaryscale waves, but also by amplification of these planetaryscale waves through tropically induced extratropical diabatic heating anomaly. Therefore, we hypothesize that during SWI days, there is a latent heat-circulation relay process that takes place as follows: tropical latent heating anomalies excite extratropical circulation anomalies; the extratropical circulation then drives extratropical latent heating anomalies by transporting moisture; the resulting extratropical latent heating, in turn, drives additional extratropical circulation. This hypothesized sequence is somewhat akin to how a hybrid vehicle operates in the sense that the tropical latent heating is analogous to gasoline fuel put into the vehicle and the extratropical latent heating is analogous to electric power generated by running the vehicle. This hypothesis of a latent heatcirculation relay is also supported by the studies of Willison et al. (2013) and Papritz and Spengler (2015) who showed that enhanced synoptic-scale wave activity is often associated with additional latent heat release.

In this study, we test the relay hypothesis in the context of the SWI by performing observational analyses and initial-value model calculations. Specifically, we address the following two questions: 1) During SWI events, what circulation and temperature anomalies are induced by the individual heating anomalies over the tropics and extratropics? 2) During SWI events, is there any evidence that tropical heating anomalies lead the extratropical heating anomalies, and then the stationary-transient wave interference? In section 2, we describe the data, analysis methods, and the setup of the idealized model experiments. The results of our observational analyses are presented in section 3, while the model results are discussed in section 4 . Last, section 5 provides a discussion and summary.

\section{Data and methods}

\section{a. Data}

Daily data of zonal wind, meridional wind, temperature, specific humidity, vertically integrated eastward/ northward moisture flux, and surface pressure have been acquired from European Centre for MediumRange Weather Forecasts (ECMWF) interim reanalysis (ERA-Interim; Dee et al. 2011). All variables are on a grid with $2.5^{\circ} \times 2.5^{\circ}$ horizontal resolution and with 23 pressure levels, except for the vertically integrated moisture flux and surface pressure. The time period examined here is December-February (DJF) for years 1979-2014. For our study, latent heating generated by convection and large-scale condensation are important variables. Because these individual latent heating variables are unavailable in the ERA-Interim data, we use diabatic heating data provided by the Japanese 55-year Reanalysis (JRA-55; Kobayashi et al. 2015) with a $2.5^{\circ} \times 2.5^{\circ}$ horizontal resolution and 37 pressure levels.

There are differences in the climatological diabatic heating among different reanalysis datasets (Ling and Zhang 2013; Wright and Fueglistaler 2013). However, Clark and Feldstein (2019, manuscript submitted to J. Atmos. Sci.) show excellent agreement in nonradiative diabatic heating between ERA-Interim and JRA-55 in their North Atlantic Oscillation (NAO) composites. This comparison is possible because the ERA-Interim provides total diabatic heating and radiative heating; nonradiative diabatic heating was computed by subtracting radiative heating from the total diabatic heating. In the JRA-55 data, the nonradiative diabatic heating was computed by summing the convective heating $Q_{\text {cnv }}$ large-scale condensational heating $Q_{\mathrm{lrg}}$, and subgrid-scale vertical diffusion. Also, Zhang et al. (2017) calculated the composite values of nonradiative diabatic heating against outgoing longwave radiation over the western Pacific at $400 \mathrm{hPa}$ from ERA-Interim, JRA-55, and the Modern-Era Retrospective Analysis for Research and Applications, version 2 (MERRA-2), and found that the agreement between ERA-Interim and JRA-55 stood out. As a further test to ascertain that our results are insensitive to the choice of the dataset, we computed the stationary wave index (defined in section 2b) using JRA-55 and compared it with the same index computed using the ERA-Interim data. The correlation coefficient between the two time series turned out to be 0.964 . In addition, the 
300-hPa streamfunction anomaly composites (not shown) from the JRA-55 dataset are essentially indistinguishable from those from the ERA-Interim (Fig. 1). These results lend confidence that JRA-55 $Q_{\mathrm{cnv}}+Q_{\mathrm{lrg}}$ can be used to investigate the relationship between the latent heating and the circulation.

\section{b. Stationary wave index and diabatic heating index}

Following GFL, we employ the projection method of Feldstein (2002) to quantify the intensity of wave interference:

$$
P_{\mathrm{SW}}(t)=\frac{\sum_{i} \sum_{j} \Psi^{\prime}\left(\lambda_{i}, \theta_{j}, t\right) \overline{\Psi^{*}}\left(\lambda_{i}, \theta_{j}, d\right) \cos \theta}{\sum_{i} \sum_{j} \overline{\Psi^{*}}\left(\lambda_{i}, \theta_{j}, d\right)^{2} \cos \theta},
$$

where $P_{\mathrm{SW}}(t)$ represents the projection time series of stationary wave for a specific day $t$, and $d$ is determined by converting $t$ to the corresponding day of the year; $\bar{\Psi}$ indicates the annual cycle, obtained by calculating the calendar-day mean of the 300-hPa streamfunction $\Psi$, and $\overline{\Psi^{*}}$ denotes the zonal-mean removed annual cycle, thus the 300-hPa climatological stationary wave. The variables $\lambda$ and $\theta$ represent the longitude at zonal grid point $i$ and the latitude at meridional grid point $j$, respectively. We calculate the daily $300-\mathrm{hPa}$ streamfunction anomalies $\Psi^{\prime}$ by subtracting the annual cycle $\bar{\Psi}$ from the daily $300-\mathrm{hPa}$ streamfunction $\Psi$. If there is constructive (destructive) interference at a given day, the projection value is positive (negative). More details on calculating the climatological streamfunction can be found in GFL. Finally, $P_{\mathrm{SW}}(t)$ is normalized by its standard deviation during DJF to generate the daily SWI.

In a manner similar to that for the SWI construction, a daily projection time series for tropical, North Pacific, and North Atlantic latent heating anomalies are computed by using the following Eq. (2). For the sake of conciseness, henceforth, we use the term heating to refer to the summation of $Q_{\mathrm{cnv}}$ and $Q_{\mathrm{lrg}}$, vertically averaged (pressure weighted) from 950 to $150 \mathrm{hPa}$, and denoted by $Q$ :

$$
P_{Q}(t)=\frac{\sum_{i} \sum_{j} Q^{\prime}\left(\lambda_{i}, \theta_{j}, t\right) \overline{Q_{\mathrm{SWI}}}\left(\lambda_{i}, \theta_{j}\right) \cos \theta}{\sum_{i} \sum_{j} \overline{Q_{\mathrm{SWI}}}\left(\lambda_{i}, \theta_{j}\right)^{2} \cos \theta}
$$

where $Q^{\prime}$ is the daily diabatic heating anomaly field obtained by subtracting the smoothed calendar-day climatology of $Q$ to remove the seasonal cycle. The $\overline{Q_{\text {SWI }}}$ is the time average of the anomalous heating field during the days when either constructive interference (SWI $>1.0$, hereafter SWI + ) or destructive interference (SWI $<-1.0$, hereafter SWI-) occurs.
For the projection domains $\left(\lambda_{i}, \theta_{j}\right)$, we define the tropics as $30^{\circ} \mathrm{S}-30^{\circ} \mathrm{N}, 0^{\circ}-360^{\circ} \mathrm{E}$, and the North Pacific (North Atlantic) domain as latitudes between $30^{\circ}$ and $70^{\circ} \mathrm{N}\left(30^{\circ}\right.$ and $\left.80^{\circ} \mathrm{N}\right)$ and longitudes between $150^{\circ}$ and $260^{\circ} \mathrm{E}\left(280^{\circ}\right.$ and $360^{\circ} \mathrm{E}$ ). The North Pacific (North Atlantic) domain is indicated by the yellow (green) box in Fig. 1j. As was shown by GFL, tropical diabatic heating associated with the SWI tends to peak during lag days -10 to 0 relative to the peak of SWI, where lag day 0 corresponds to the days when SWI exceeds one standard deviation. Therefore, for the tropical domain, $\overline{Q_{\text {SWI }}}$ is obtained by averaging the anomalous heating field from lag days -10 to 0 . Figure 1 show that organized extratropical heating anomalies tend to become established several days after the warm pool heating. For the North Pacific (North Atlantic) domain, $\overline{Q_{\text {SWI }}}$ is obtained by averaging from lag days -6 to 0 (lag days -6 to +3 ). Once again, the resulting daily projection time series from Eq. (2) are normalized, and the results are referred to as the tropical heating index, which is denoted as $\mathcal{T}^{+}\left(\mathcal{T}^{-}\right)$if $\overline{Q_{\text {SWI }}}$ is the tropical heating anomalies during the SWI+ (SWI-) days. Similarly, if $\overline{Q_{\text {SWI }}}$ is the North Pacific heating anomalies during the SWI+ (SWI-) days the normalized projection is referred to as the North Pacific heating index, and denoted as $P^{+}\left(P^{-}\right)$; for the North Atlantic heating anomalies, the resulting indices are denoted as $A^{+}\left(A^{-}\right)$for SWI+ (SWI-) days. The time evolution of daily heating indices relative to the daily SWI is presented in Fig. 2. Consistent with the aforementioned temporal behavior of the regional heating, which is based on a visual inspection of Fig. 1, Fig. 2a (for SWI+) and Fig. $2 b$ (for SWI-) show that tropical heating anomalies lead the extratropical anomalies by about 5 days.

\section{c. Binning procedure-based heating indices}

Last, to answer the first question posed in section 1, we divided the SWI days into multiple bins by sorting them based on the magnitude of the three heating indices. Because tropical heating anomalies occur first (Fig. 2), the tropical heating index is used as the first criterion for creating the bins. For example, all SWI+ days are divided into three bins, with the first bin corresponding to those SWI+ days with the top one-third of the $\mathcal{T}^{+}$values, and the second and third bin corresponding to SWI+ days with the middle and bottom one-third of the $\mathcal{T}^{+}$values, respectively. We denote the first bin as $\mathcal{T}_{T}^{+}$and the third bin as $\mathcal{T}_{B}^{+}$, where the subscript $T(B)$ stands for top (bottom) one-third. The results for the second bin show characteristics that are between those of the first and third bins; hence, they are not presented.

The North Pacific (Atlantic) domain is then used as the second (third) criterion. For these extratropical heating criteria, only two bins are used to retain a 


\section{Lag-composites of PSI300 and Diabatic heating during SWI > 1.0 (502 days)}
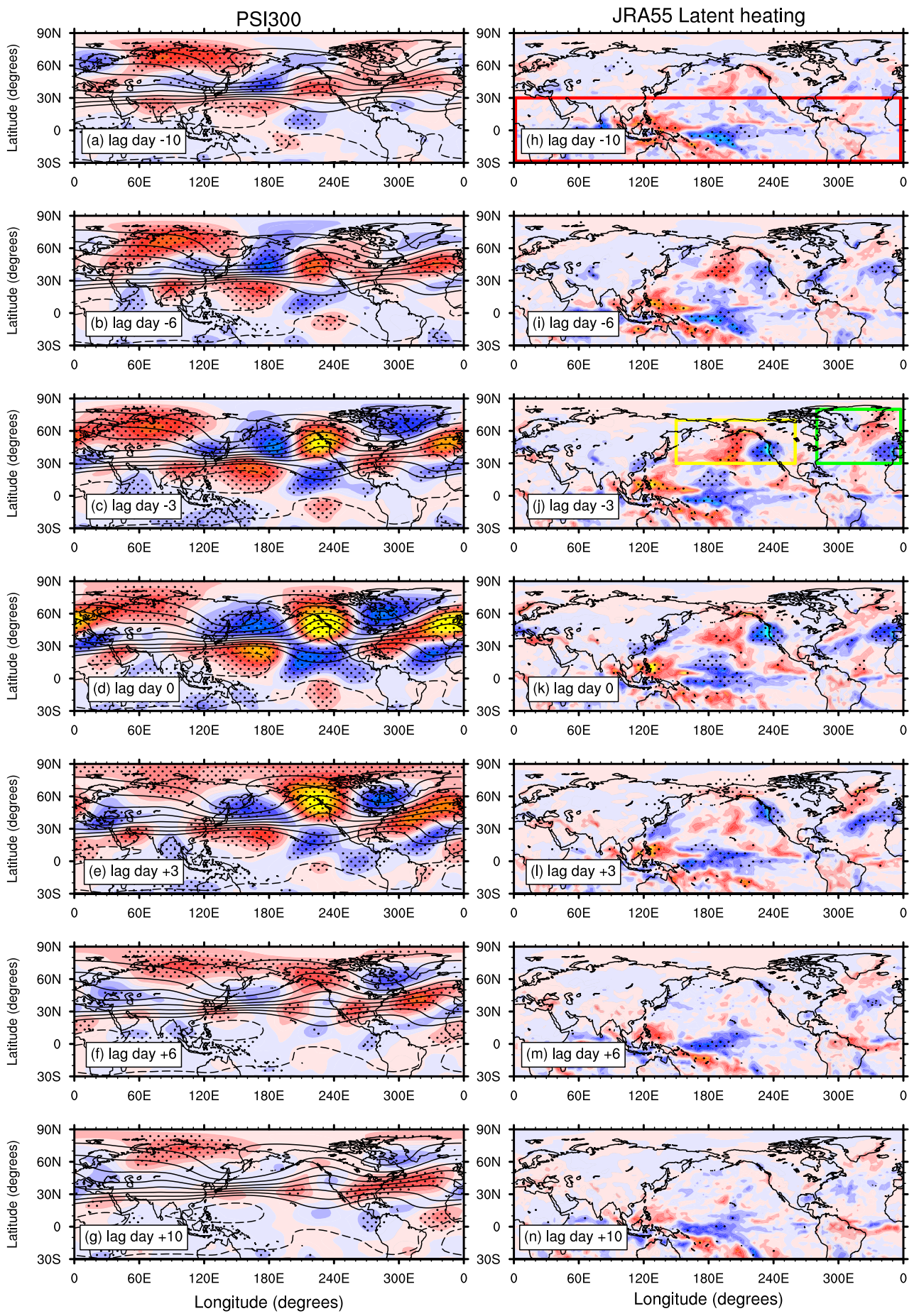

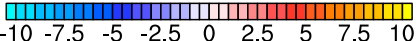

$300-\mathrm{hPa}$ streamfunction anomaly $\left(10^{6} \mathrm{~m}^{2} \mathrm{~s}^{-1}\right)$

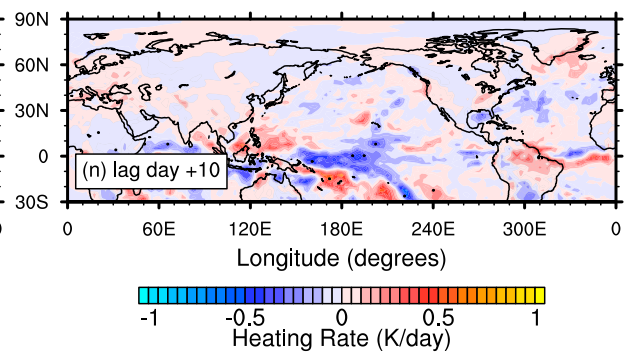

FIG. 1. (a)-(g) Total 300-hPa streamfunction (contours, interval of $1.5 \times 10^{7} \mathrm{~m}^{2} \mathrm{~s}^{-1}$ ) and anomalies (shading), and (h)-(n) vertically averaged latent heating anomalies during the SWI+ days. Dotted areas indicate statistical significance at the $10 \%$ level. Statistical significance is evaluated by employing a Monte Carlo simulation with 1000 random samples. 
$\mathrm{SWI}>1.0$
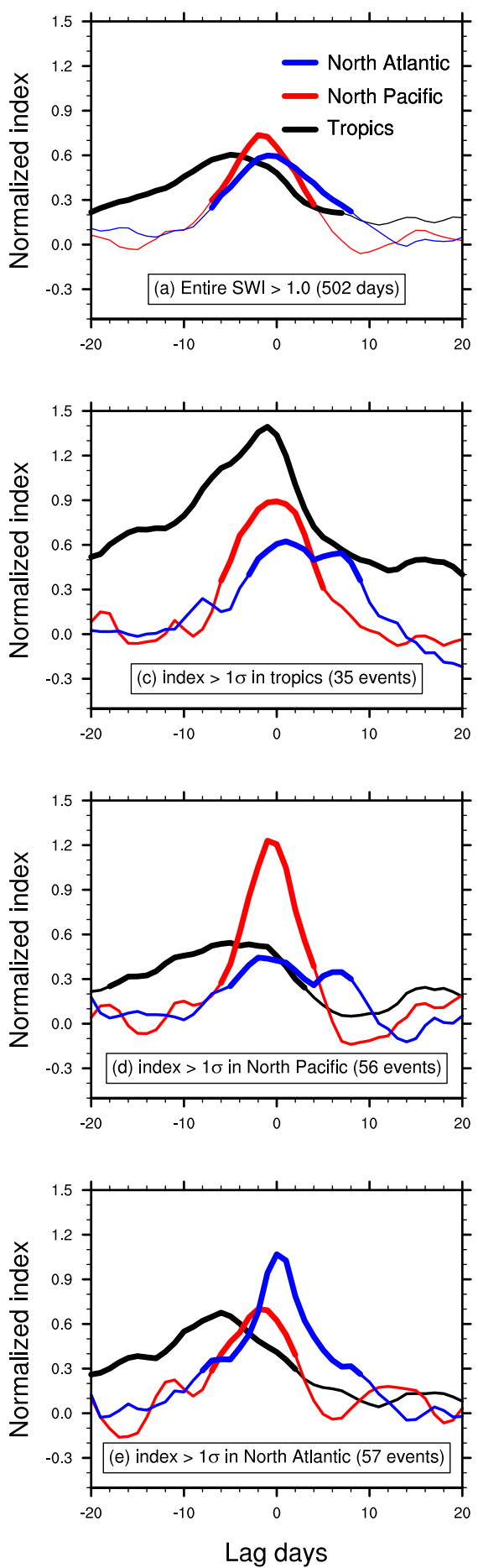

$\mathrm{SWI}<-1.0$
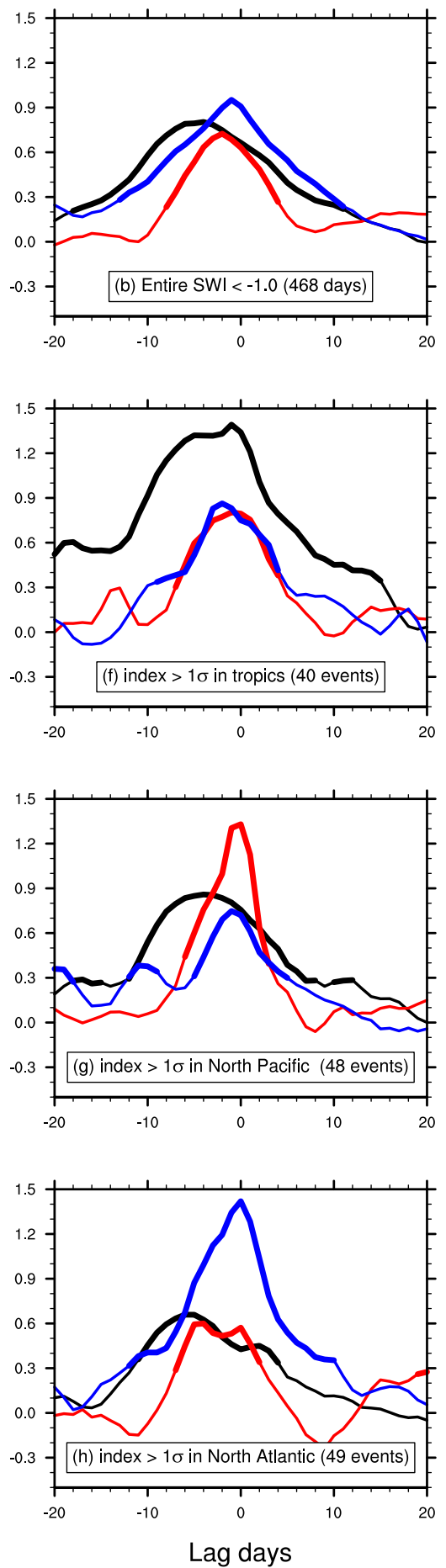

FIG. 2. Lag composites of daily heating indices (black for tropical, red for North Pacific, and blue for North Atlantic) during (left) SWI+ and (right) SWI- days. Row are composites during (a),(b) entire SWI days, (c),(f) SWI and tropical heating index $>1 \sigma$ days, (d), (g) SWI and North Pacific heating index $>1 \sigma$ days, and (e),(h) SWI and North Atlantic heating index $>1 \sigma$ days. A 3-day running mean was applied to the heating fields shown in (c)-(h). A Monte Carlo simulation with 1000 random samples is performed for the statistical significance test, and the thick lines indicate statistical significance at the $5 \%$ level. 
TABLE 1. Acronym definitions after binning procedures and the number of DJF days in each bin out of 3249 all DJF days.

\begin{tabular}{|c|c|c|c|}
\hline Acronym & Definition & Number of days & Number of events \\
\hline SWI+ & SWI greater than 1.0 & 502 & - \\
\hline SWI- & SWI less than -1.0 & 468 & - \\
\hline$E_{T} \mid \mathcal{T}_{T}^{+}$ & $\begin{array}{l}\text { Top one-half of extratropical heating bin among top one-third of } \\
\text { tropical heating bin during SWI+ days }\end{array}$ & 41 & 20 \\
\hline$E_{B} \mid \mathcal{T}_{T}^{+}$ & $\begin{array}{l}\text { Bottom one-half of extratropical heating bin among top one-third } \\
\text { of tropical heating bin during SWI+ days }\end{array}$ & 41 & 26 \\
\hline$E_{T} \mid \mathcal{T}_{B}^{+}$ & $\begin{array}{l}\text { Top one-half of extratropical heating bin among bottom one-third } \\
\text { of tropical heating bin during SWI+ days }\end{array}$ & 41 & 24 \\
\hline$E_{B} \mid \mathcal{T}_{B}^{+}$ & $\begin{array}{l}\text { Bottom one-half of extratropical heating bin among bottom } \\
\text { one-third of tropical heating bin during SWI + days }\end{array}$ & 41 & 26 \\
\hline$E_{T} \mid \mathcal{T}_{T}^{-}$ & $\begin{array}{l}\text { Top one-half of extratropical heating bin among top one-third of } \\
\text { tropical heating bin during SWI- days }\end{array}$ & 39 & 15 \\
\hline$E_{B} \mid \mathcal{T}_{T}^{-}$ & $\begin{array}{l}\text { Bottom one-half of extratropical heating bin among top one-third } \\
\text { of tropical heating bin during SWI- days }\end{array}$ & 39 & 21 \\
\hline$E_{T} \mid \mathcal{T}_{B}^{-}$ & $\begin{array}{l}\text { Top one-half of extratropical heating bin among bottom one-third } \\
\text { of tropical heating bin during SWI- days }\end{array}$ & 39 & 21 \\
\hline$E_{B} \mid \mathcal{T}_{B}^{-}$ & $\begin{array}{l}\text { Bottom one-half of extratropical heating bin among bottom } \\
\text { one-third of tropical heating bin during SWI- days }\end{array}$ & 39 & 22 \\
\hline
\end{tabular}

sufficient number of SWI days in each of the bins; within the $\mathcal{T}_{T}^{+}$bin, the SWI+ days are divided into two additional bins ranked by $P$. This procedure generates two secondary bins $P_{T} \mid \mathcal{T}_{T}^{+}$and $P_{B} \mid \mathcal{T}_{T}^{+}$, where $A \mid B$ denotes condition $A$ at given condition $B$. For example, $P_{T} \mid \mathcal{T}_{T}^{+}$ denotes the top one-half of Pacific heating days among the top one-third of tropical heating SWI+ days. The $P_{T} \mid \mathcal{T}_{T}^{+}$bin is further divided into two additional bins according to the Atlantic heating index: $A_{T}\left|P_{T}\right| \mathcal{T}_{T}^{+}$and $A_{B}\left|P_{T}\right| \mathcal{T}_{T}^{+}$, where the former (latter) denotes the top (bottom) one-half of Atlantic heating days in the $P_{T} \mid \mathcal{T}_{T}^{+}$ bin. Ultimately, this procedure yields four tertiary bins for the $\mathcal{T}_{T}^{+}$bin: $A_{T}\left|P_{T}\right| \mathcal{T}_{T}^{+}, A_{B}\left|P_{T}\right| \mathcal{T}_{T}^{+}, A_{T}\left|P_{B}\right| \mathcal{T}_{T}^{+}$, and $A_{B}\left|P_{B}\right| \mathcal{T}_{T}^{+}$. The behavior of the SWI+ days in all four bins are worthy of investigation, but to address the questions raised in section 1, our analysis will be limited to $A_{T}\left|P_{T}\right| \mathcal{T}_{T}^{+}$and $A_{B}\left|P_{B}\right| \mathcal{T}_{T}^{+}$bins. If the Atlantic heating index is used as the second criterion to create $P_{T}\left|A_{T}\right| \mathcal{T}_{T}^{+}$ and $P_{B}\left|A_{B}\right| \mathcal{T}_{T}^{+}$bins, the SWI+ days that belong to these bins overlap with the SWI+ days in $A_{T}\left|P_{T}\right| \mathcal{T}_{T}^{+}$and $A_{B}\left|P_{B}\right| \mathcal{T}_{T}^{+}$by $95 \%$ and $87.5 \%$, respectively, indicating that the membership of the SWI+ days is qualitatively insensitive to the order that the Pacific and Atlantic heating criteria are applied. Therefore, henceforth we denote $A_{T}\left|P_{T}\right| \mathcal{T}_{T}^{+}$as $E_{T} \mid \mathcal{T}_{T}^{+}$and $A_{B}\left|P_{B}\right| \mathcal{T}_{T}^{+}$as $E_{B} \mid \mathcal{T}_{T}^{+}$, where $E$ stands for extratropics. The same procedure is applied to $\mathcal{T}_{B}^{+}$, yielding four tertiary bins. For our purpose, again, $A_{T}\left|P_{T}\right| \mathcal{T}_{B}^{+}$and $A_{B}\left|P_{B}\right| \mathcal{T}_{B}^{+}$bins are analyzed, which will be denoted as $E_{T} \mid \mathcal{T}_{B}^{+}$and $E_{B} \mid \mathcal{T}_{B}^{+}$bins, respectively.

Summarizing the binning procedure, SWI+ days are divided into multiple bins and, among these bins, we analyze $E_{T}\left|\mathcal{T}_{T}^{+}, E_{B}\right| \mathcal{T}_{T}^{+}, E_{T} \mid \mathcal{T}_{B}^{+}$, and $E_{B} \mid \mathcal{T}_{B}^{+}$bins. These four bins, respectively, represent the SWI+ days when both tropical and extratropical heating are relatively strong, the SWI+ days when tropical heating is strong and extratropical heating is weak, the SWI+ days when tropical heating is weak and extratropical heating is strong, and the SWI+ days when both tropical and extratropical heating are weak. Using the same procedure, SWI- days are also divided into multiple bins and four of those bins are examined: $E_{T}\left|\mathcal{T}_{T}^{-}, E_{B}\right| \mathcal{T}_{T}^{-}, E_{T} \mid \mathcal{T}_{B}^{-}$, and $E_{B} \mid \mathcal{T}_{B}^{-}$. The criteria of the eight bins analyzed in this study are summarized in Table 1 .

For the purpose of analyzing time sequence of events, we identify individual events based on the following procedures. For each bin, an SWI event is defined as a 15-day time interval that contains at least one SWI day that satisfies the binning criteria and the day of the maximum (or minimum for destructive interference) SWI value. The eighth day within the 15-day interval coincides with the maximum or minimum SWI value, and is defined as the SWI lag 0 days. With this definition, consecutive SWI events are separated from each other by at least 7 days. For the statistical significance of the composite values presented in Figs. 1-5, Monte Carlo simulations are performed. For composites based on $N$ number of events, we generated 1000 composites, with each composite consisting of $N$ randomly chosen events with each event having a time interval extending from lag -10 to lag +10 days (Fig. 1) and from lag -20 to lag +20 days (Figs. 2-5). A null distribution was then constructed from the 1000 random composites for each lag day, and the $p$ value of the observed composite was computed based on the distribution. Again following GFL, to account for the fact 
that the consecutive days are not independent of each other, for Fig. 1, we divided $N$ number of days by 3.38 and rounded to the nearest integer. In Fig. 1, the stippled region indicates statistical significance at the $p<0.10$ level, while in Figs. 2-5, the $p<0.05$ level is indicated.

\section{d. Model experiment setup}

To test the causal relationships that emerge from our diagnostic analyses, we utilize the spectral dynamic core from the NOAA Geophysical Fluid Dynamics Laboratory (GFDL). The same model setup as in Baggett et al. (2016) is used in this study: a horizontal resolution of triangular 42, a vertical resolution of 28 sigma levels, a damping time scale of 0.1 days at its smallest scale for a fourth-order horizontal diffusion, Newtonian cooling, and Rayleigh friction parameterized as in Held and Suarez (1994). The climatological DJF values of zonal wind, meridional wind, temperature, and surface pressure are used as the initial background state. For passive tracer experiments, we use the zonal-mean climatological specific humidity field. To ensure that the zonally varying DJF climatological state is a solution to the model equations, we add a forcing term that is obtained by integrating the model by one time step starting from the climatological state. This forcing term prevents the model from drifting from the initial state (the DJF climatological state) unless additional forcing (e.g., diabatic heating) is added. Additional details on the model setup and limitations can be found in Franzke et al. (2004). In the control experiment, the model is integrated without any additional forcing, whereas for perturbation experiments, the model is forced by time-dependent (lag days -10 to +7$) E_{T} \mid \mathcal{T}_{T}^{+}$composite heating (Fig. 3a): at model day 1 , the forcing incorporated into the model integration is the lag day -10 composite; at model day 2 , the forcing is lag day -9 composite, and so on. Each model experiment was run for 25 days. The diabatic heating composites, computed at the JRA-55's 37 pressure levels, are interpolated into model's 28 sigma levels.

\section{Observational analysis}

\section{a. Relationship between circulation and heating anomalies during SWI}

We first examine the 300-hPa streamfunction evolution for SWI+ days (Figs. 1a-g). Because GFL provides a detailed description of the same fields, we present just a few key highlights pertinent to this study. It can be seen that the streamfunction anomalies (shading) in Fig. 1 grow and decay over a period of about two weeks. For the SWI+, by construction, the positive (negative) anomalies coincide with the climatological ridges (troughs). The opposite is the case for the SWI composites (see Fig. S1 in the online supplemental material). Poleward of $50^{\circ} \mathrm{N}$, there are two ridges, one centered at the eastern end of Gulf of Alaska and the other centered over the British Isles. As such, associated with these ridges, there are southerly flows over the two ocean corridors to the Arctic Ocean, one over the Bering Sea and the other over the Norwegian Sea.

Figures $1 \mathrm{~h}-\mathrm{n}$ illustrate the composite heating anomalies during SWI+ days. When there is constructive interference, consistent with GFL, there is enhanced warm-pool convection and suppressed convection in central tropical Pacific, reinforcing the zonal asymmetry of the climatological heating field. In the extratropics, which was not examined by GFL, a positive anomaly is seen over the central North Pacific, while a negative anomaly is found over the eastern North Pacific and western North America. These heating anomalies appear at lag day -6 and dissipate during positive lag days (Figs. 1i-m). We also see heating anomalies over the northeastern Atlantic and cooling over subtropical Atlantic shortly after the North Pacific heating is excited. In the case of destructive interference, SWI-, streamfunction and heating anomalies with the opposite signs are found over the tropics and extratropics (see Fig. S1).

Synthesizing the results of the streamfunction and heating field composites, we highlight two findings: First, the SWI+ (SWI-) heating anomaly field reinforces (dampens) the zonally asymmetric component of climatological diabatic heating (e.g., Fig. 8 of Held et al. 2002). This relationship suggests that a strengthening of the zonally asymmetric component of the climatological diabatic heating leads to an amplification of the climatological stationary wave. Because diabatic heating is a major driver of the climatological stationary wave, this transient heating-SWI relationship is consistent with stationary wave theory (e.g., Held et al. 2002; Chang 2009). Second, as was briefly discussed in the previous section, the tropical heating anomalies tend to precede the extratropical heating anomalies by several days, suggesting that the SWI extratropical heating anomalies are, at least in part, driven by the circulation driven by the tropical heating anomalies. As a first step to explore this possibility, we next examine lead-lag relationships between tropical and extratropical heating.

\section{b. Relationship between tropical and extratropical heating anomalies during SWI}

Figure 2 shows the heating index composites associated with SWI+ (left column) and SWI- (right column). We first examine composites over all SWI + and SWI- days, that is, $\mathcal{T}^{+}, P^{+}, A^{+}$(Fig. 2a) and $\mathcal{T}^{-}, P^{-}, A^{-}$(Fig. 2b). It can be seen that a strengthening of the tropical heating indices, $\mathcal{T}^{+}$and $\mathcal{T}^{-}$, starting lag day -20 , reaching a peak at 


\section{Latent Heating anomaly averaged from lag -10 to 3}
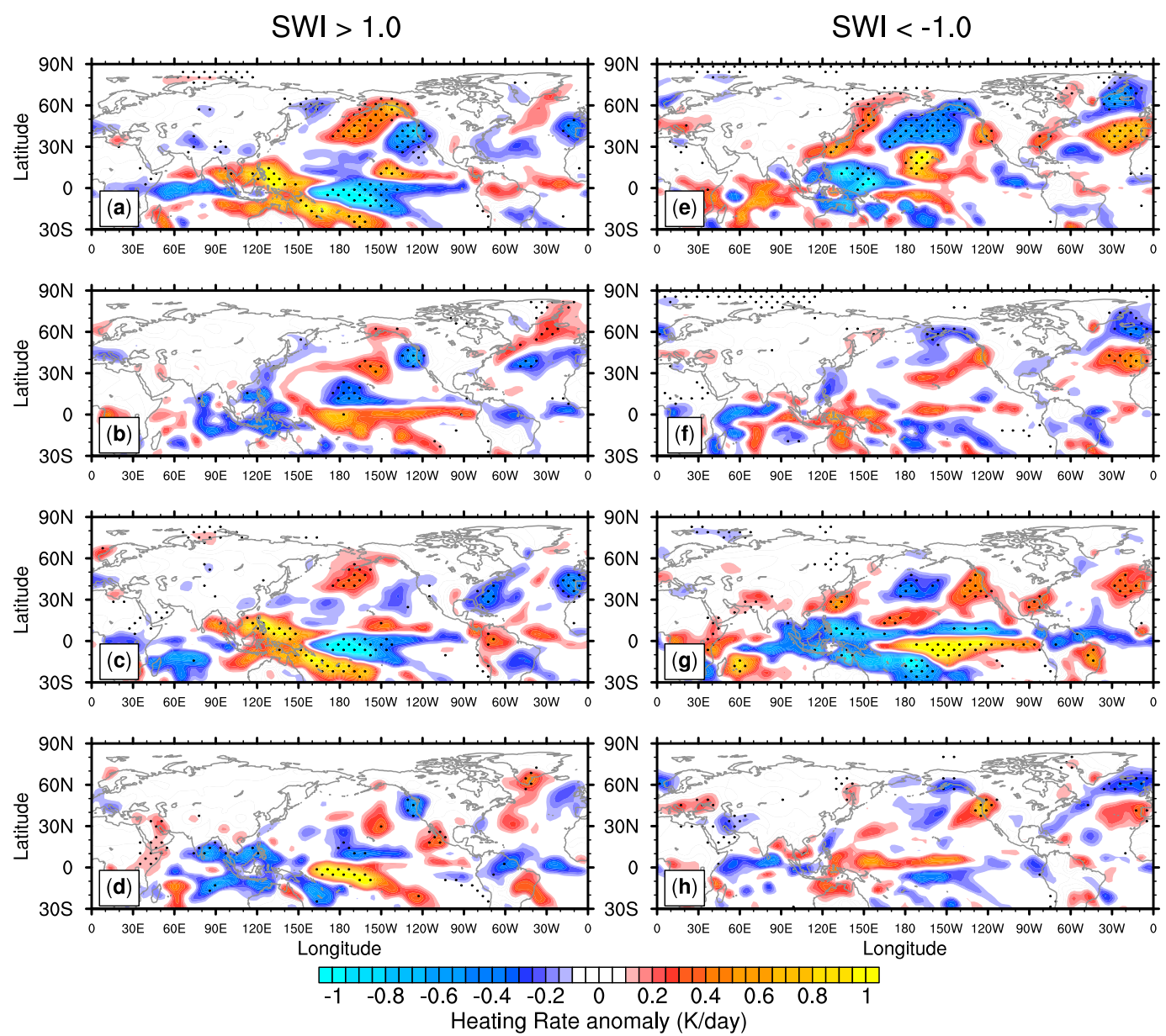

FIG. 3. Composites of latent heating anomalies averaged from lag days -10 to +3 in (a) $E_{T} \mid \mathcal{T}_{T}^{+}$, (b) $E_{T} \mid \mathcal{T}_{B}^{+}$, (c) $E_{B} \mid \mathcal{T}_{T}^{+}$, (d) $E_{B} \mid \mathcal{T}_{B}^{+}$, (e) $E_{T} \mid \mathcal{T}_{T}^{-}$, (f) $E_{T} \mid \mathcal{T}_{B}^{-}$, (g) $E_{B} \mid \mathcal{T}_{T}^{-}$, and (h) $E_{B} \mid \mathcal{T}_{B}^{-}$(see Table 1 for details on each acronym). A Monte Carlo simulation with 1000 random samples is performed for the statistical significance test, and the dotted areas indicate statistical significance at the $5 \%$ level. Prior to the statistical significance test, a nine-point local smoothing was applied twice to the composites.

around lag day -5 , while the North Pacific heating indices, $P^{+}$and $P^{-}$, show statistically significant values between lag day -8 and +6 , and peaking at lag day -1 . Although there are some differences in the time evolution of the North Atlantic heating indices, $A^{+}$and $A^{-}$, both indices slightly lag their respective North Pacific indices. However, even during the SWI+ days, not all tropical heating anomalies would be followed by the extratropical heating anomalies, and not all extratropical heating anomalies would be preceded by the tropical heating anomalies.

As a way to evaluate the extent of the association among these three heating anomalies, the aforementioned composite analysis was repeated, first with the condition that $\mathcal{T}^{+}>1$ (Fig. 2c) and $\mathcal{T}^{-}>1$ (Fig. 2f); second with the condition that $P^{+}>1$ (Fig. 2d) and $P^{-}>1$ (Fig. $2 \mathrm{~g}$ ); and third the condition that $A^{+}>1$
(Fig. 2e) and $A^{-}>1$ (Fig. 2h). The results show that in all three cases, the onset of tropical heating precedes that of extratropical heating by nearly 10 days. Focusing on the SWI + days, we find that the statistically significant $P^{+}$ values also precede statistically significant $A^{+}$values by approximately 3 days. Therefore, we hypothesize the following causal relationships during SWI+ days: tropical heating tends to excite a circulation that enhances extratropical heating, and the North Pacific heating further enhances the North Atlantic heating. This relay hypothesis will be addressed in section 4 using initial-value calculations.

\section{c. Four types of heating anomalies during SWI and associated circulation pattern}

Before presenting results from the model calculations, we first examine the structure of the heating and 
circulation anomalies for the following cases: $E_{T} \mid \mathcal{T}_{T}^{+}$, $E_{B}\left|\mathcal{T}_{T}^{+}, E_{T}\right| \mathcal{T}_{B}^{+}$, and $E_{B} \mid \mathcal{T}_{B}^{+}$for the SWI+ days, and $E_{T}\left|\mathcal{T}_{T}^{-}, E_{B}\right| \mathcal{T}_{T}^{-}, E_{T} \mid \mathcal{T}_{B}^{-}$, and $E_{B} \mid \mathcal{T}_{B}^{-}$for the SWI- days (see section $2 \mathrm{c}$ for details). Figure 3 shows the composite heating anomalies averaged from lag days -10 to +3 in each bin during SWI+ (left column) or SWI- (right column). Every panel displays statistically significant anomalies in the tropics and the midlatitude storm-track regions. In the two $\mathcal{T}_{T}^{+}$bins, we see La Niña-like features-enhanced convection over the Maritime Continent and suppressed convection over the central tropical Pacific (Figs. 3a,c). The $\mathcal{T}_{B}^{+}$bins, on the other hand, show El Niño-like heating pattern (Figs. 3b,d). The $E_{B} \mid \mathcal{T}_{B}^{+}$ bin (Fig. 3d) shows that stationary wave interference can occur without significant diabatic heating anomalies. Destructive interference composites show opposite sign anomalies, suggesting a linear relationship between the heating and the SWI anomalies.

The zonal asymmetry in the heating anomalies suggests that the SWI events might be influenced by the MaddenJulian oscillation (MJO; Madden and Julian 1971), which is a 30-60-day tropical variability with eastwardpropagating convection. By calculating the composites of the real-time multivariate MJO (RMM; Wheeler and Hendon 2004) indices for each bin, we found that in the $\mathcal{T}_{T}^{+}$events the MJO phase 3-4 signal can be detected starting lag day -20 and the signal reaches phase 6 by lag day 0 . For the $E_{T} \mid \mathcal{T}_{T}^{+}$events, the RMM values are statistically significant only briefly at lag day -5 when it resides in phase 5 . The $E_{T} \mid \mathcal{T}_{B}^{+}$events tend to occur during the same MJO phases as the $E_{T} \mid \mathcal{T}_{T}^{+}$ events, but with smaller amplitudes. The $E_{B} \mid \mathcal{T}_{B}^{+}$events typically start with phase 6 (lag day -20$)$ and end with phase 2 (lag day +20 ), with little statistical significance (not shown).

Figure 4 shows the 300-hPa streamfunction anomalies in each bin, averaged from lag days -1 to +1 . We overlay vectors of vertically integrated moisture flux poleward of $30^{\circ} \mathrm{N}$. In all four bins of SWI,$+ \Psi^{\prime}$ (shading) reinforces $\Psi$ (black contours). However, there are some differences. Figures $4 \mathrm{a}-\mathrm{d}$ reveal that intense moisture transport into the Arctic is present in the $\mathcal{T}_{T}^{+}$bins (Figs. 4a,c), whereas it is generally weaker and trapped in the midlatitudes in the two $\mathcal{T}_{B}^{+}$bins (Figs. 4b,d). The largest moisture flux is found in the $E_{T} \mid \mathcal{T}_{T}^{+}$bin (Fig. 4a), while the weakest vectors are found particularly over the North Pacific in the $E_{B} \mid \mathcal{T}_{B}^{+}$bin (Fig. 4d). During the SWI- days, there are generally negative moisture flux anomalies propagating out of the Arctic, and also the flux anomalies are strongest in the $E_{T} \mid \mathcal{T}_{T}^{-}$bin (Fig. 4e).

Figure 5 presents temperature anomalies averaged vertically between 700 and $1000 \mathrm{hPa}$. During the 5 days following the SWI events (left column), every bin shows warming at least either over the Pacific or the Atlantic sector of Arctic Ocean. In later lag days, however, Arctic warming is observed only in the $\mathcal{T}_{T}^{+}$bins (right column). Moreover, the $\mathcal{T}_{T}^{+}$bins show a "warm Arctic-cold continents" pattern (Overland et al. 2011). The SWI- cases show features that are essentially the same but opposite in sign (not shown). To further quantify the relationship between SWI and Arctic warming in each heating bin, we constructed lag composites of lower-tropospheric temperature anomaly averaged poleward of $70^{\circ} \mathrm{N}$ and the corresponding SWI (see Fig. S2). During SWI+, the Arctic warming persists out to +16 days in the $\mathcal{T}_{T}^{+}$bins for the zonal-mean anomalies, but not in the $E_{T} \mid \mathcal{T}_{B}^{+}$ cases. The warming in the $E_{T} \mid \mathcal{T}_{B}^{+}$bin persists only until lag day +7 , and the $E_{B} \mid \mathcal{T}_{B}^{+}$bin shows no significant zonal-mean temperature anomaly throughout the period. This result suggests that tropical heating is important for prolonged Arctic warming. For the SWI- days, The most prolonged Arctic cooling occurs in the $E_{B} \mid \mathcal{T}_{T}^{-}$bin.

\section{Model results}

In this section, we use the model (see section $2 \mathrm{~d}$ for details) to test the causal relationships suggested by the observational analysis presented in the previous section. Specifically, we first ask the extent to which the SWI+ heating anomalies can explain the associated circulation and temperature anomalies. Next, we ask if the tropical heating anomalies can lead to the North Pacific and North Atlantic heating anomalies. Because water vapor is the central ingredient of latent heating, to make headway toward addressing the second question, we use a passive tracer to represent moisture. This approach is supported by the earlier studies that show that large-scale advection can account for much of the water vapor distribution in the free troposphere (Pierrehumbert et al. 2007, and references therein; Baggett et al. 2016; Ming and Held 2018).

\section{a. Circulation and temperature response}

For brevity, we only present results for the SWI+ experiments because the model responses to the SWIheating anomalies are by and large opposite to those of the SWI+ heating. We also confine our analysis to the $E_{T} \mid \mathcal{T}_{T}^{+}$case because both the tropical and extratropical heating anomalies are strong. We first examine the model $\Psi^{\prime}$ response to the time-dependent $E_{T} \mid \mathcal{T}_{T}^{+}$composite heating during model days 10-12, which corresponds to lag days -1 to +1 . Figures $6 a-c$ depict individual contributions to the $E_{T} \mid \mathcal{T}_{T}^{+}$response from 


\section{0-hPa Streamfunction anomaly averaged from lag day -1 to 1}
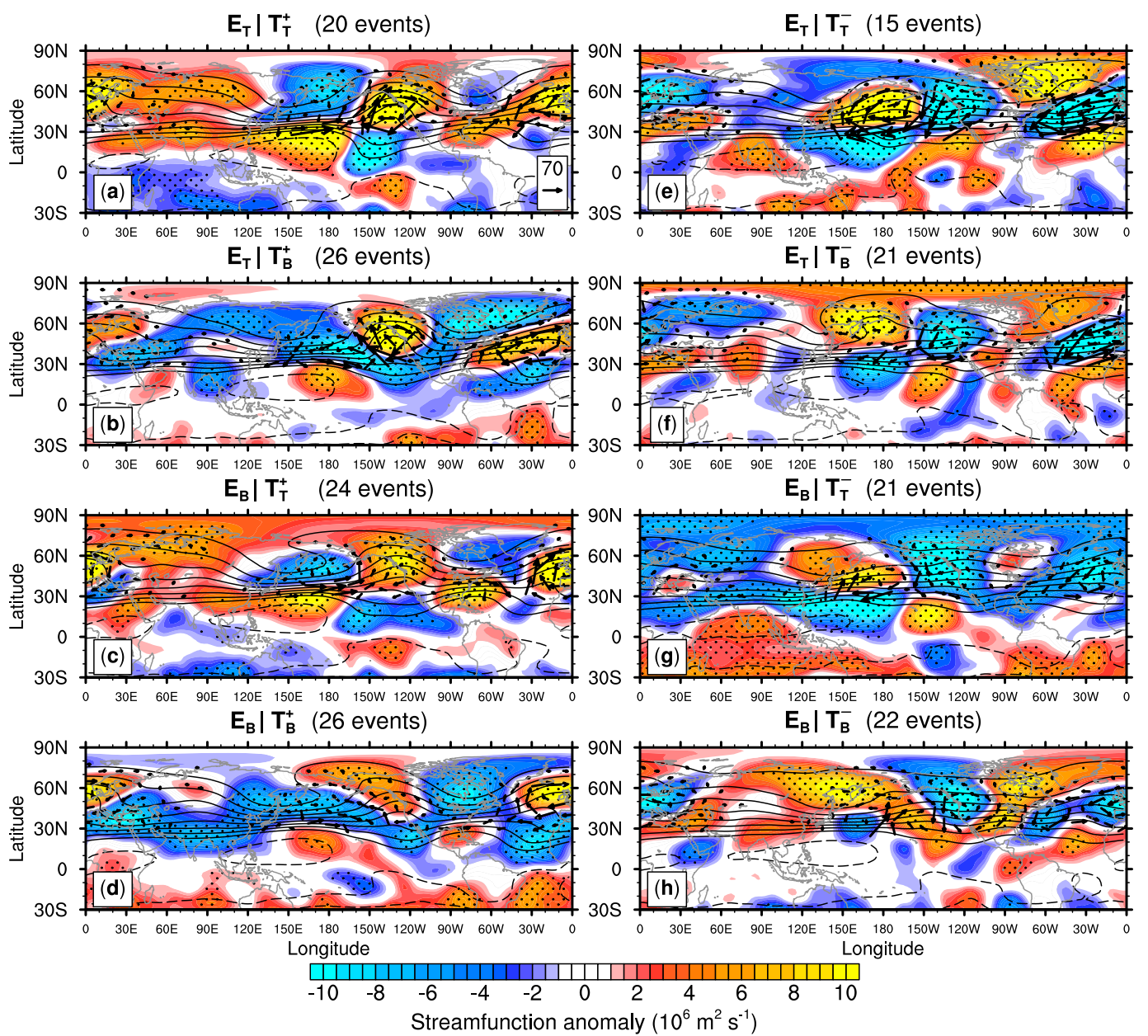

FIG. 4. Composites of $300-\mathrm{hPa}$ streamfunction anomalies (shading) averaged from lag days -1 to +1 in the same subsets as in Fig. 3, and total 300-hPa streamfunction (contours, interval of $1.5 \times 10^{7} \mathrm{~m}^{2} \mathrm{~s}^{-1}$ ). Overlaid vectors represent vertically integrated moisture flux $\left(\mathrm{kg} \mathrm{m}^{-1} \mathrm{~s}^{-1}\right)$ north of $30^{\circ} \mathrm{N}$. The vectors whose magnitude is less than $10 \mathrm{~kg} \mathrm{~m}^{-1} \mathrm{~s}^{-1}$ are omitted, and reference vector is $70 \mathrm{~kg} \mathrm{~m}^{-1} \mathrm{~s}^{-1}$. A Monte Carlo simulation with 1000 random samples is performed for the statistical significance test, and the dotted areas indicate statistical significance at the $5 \%$ level.

tropical heating, North Pacific heating, and North Atlantic heating, respectively. The summation of these three solutions, shown in Fig. 6d, closely resembles Fig. 6e, where diabatic heating is forced over the entire globe. The result indicates that the model response is mostly linear and that the heating outside of these three domains has a negligible effect on the model solution. Comparing the individual panels in Fig. 6, we see that most of the extratropical response is forced by tropical heating and North Pacific heating. Wave trains forced by tropical heating emanate from the western warm pool and eastern tropical Pacific, reaching eastern Siberia and the eastern subpolar North Atlantic (Fig. 6a), while the North Pacific heating drives a wave train that propagates equatorward and downstream of the heating, traversing North America (Fig. 6b). In Fig. 6c, the North Atlantic heating excites a wave train that spans from the subpolar North Atlantic Ocean to South Asia and another wave train from central Siberia to the western North Pacific. These modeling results suggest that for the $E_{T} \mid \mathcal{T}_{T}^{+}$events, North Pacific heating plays the central role in driving anomalies over the Arctic Ocean. Turning our attention to Figs. $6 \mathrm{~d}$ and $6 \mathrm{e}$, it can be seen that a preeminent ridge develops over Alaska and the subpolar North Atlantic, which would reinforce the climatological ridge at the same location (Fig. 1). It is also worth noting that this subpolar North Atlantic ridge is connected to the subtropical ridge 


\section{Temperature anomaly during SWI > 1.0 - Short term / Long term}
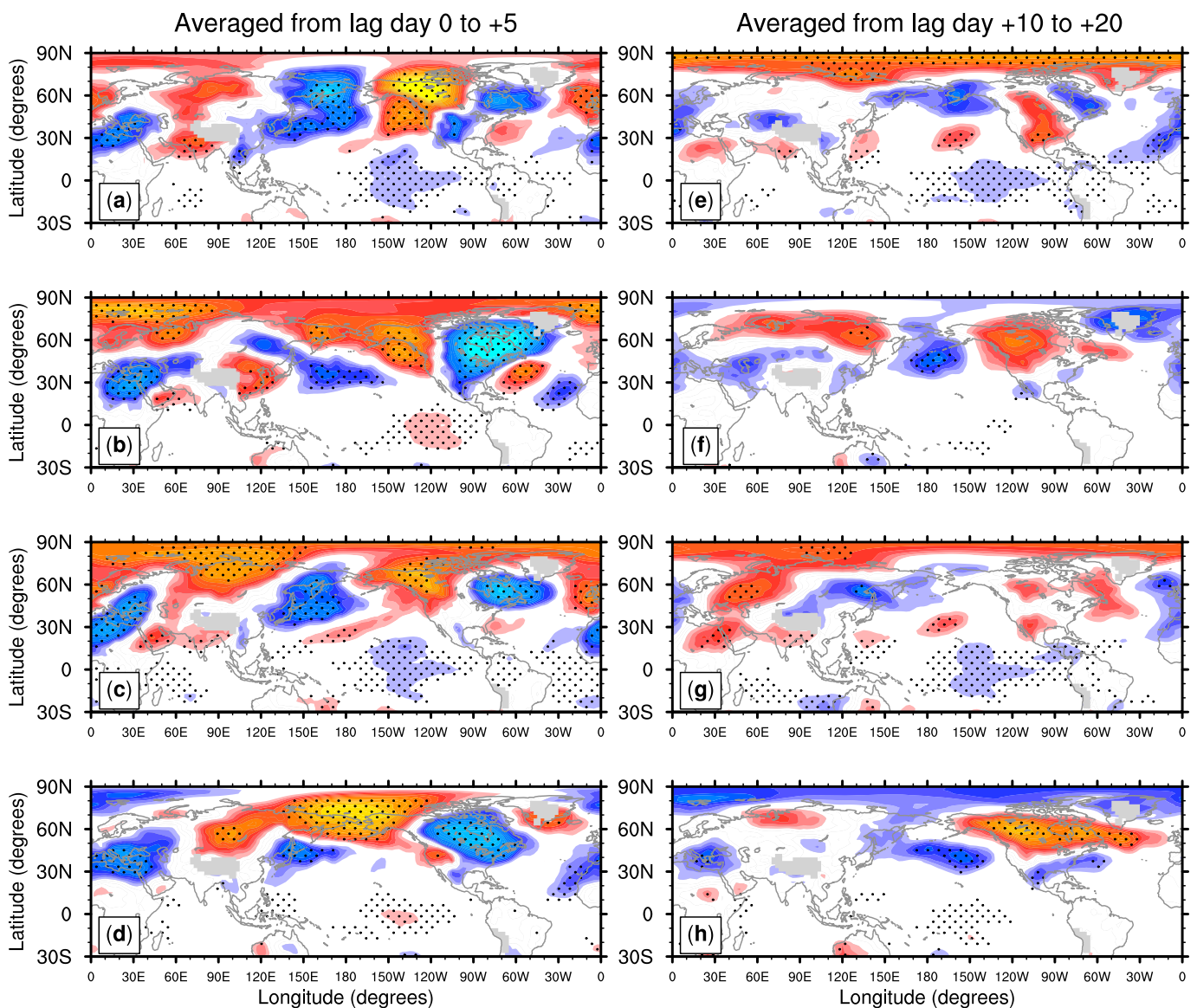

\begin{tabular}{llllllllll|l|l|l|l|l|l}
-4 & -3.2 & -2.4 & -1.6 & -0.8 & 0 & 0.8 & 1.6 & 2.4 & 3.2 & 4
\end{tabular}

Lower Tropospheric Temperature (700-1000 hPa) anomaly (K)

FIG. 5. Composites of lower-tropospheric $(700-1000 \mathrm{hPa})$ temperature anomalies during SWI+ days averaged (a)-(d) from lag days 0 to +5 and (e)-(h) from lag days +10 to +20 in the same subsets for SWI+ days as in Figs. 3a-d. Gray shading denotes the region where surface pressure is below $700 \mathrm{hPa}$. A Monte Carlo simulation with 1000 random samples is performed for the statistical significance test, and the dotted areas indicate statistical significance at the $5 \%$ level.

centered over the Gulf of Mexico in Fig. 6e. The result is a southwest-northeast-tilted ridge spanning from the Gulf of Mexico to the Greenland Sea. This tilted structure is an important characteristic of the North Atlantic stationary wave and climatological jet.

Figure 7 shows the vertically averaged $(700-1000 \mathrm{hPa})$ temperature response averaged from model days 11 to 16 , which corresponds to the lag days 0 to +5 in observation (Fig. 5a). In Fig. 7a, tropical heating causes warming over eastern Siberia and Greenland and cooling over northern Canada and the Norwegian Sea. The North Pacific heating leads to warming over a broad swath of area poleward of $50^{\circ} \mathrm{N}$, ranging from northern North America to Scandinavia, and cooling over eastern Siberia and much of the contiguous United States (Fig. 7b). Figure 7c shows that the North Atlantic heating results in warming (cooling) over the BarentsKara Seas and northern Europe (eastern Greenland and the Mediterranean Sea). Figure $7 d$ shows the sum of the three model solutions. Compared with the observation (Fig. 5a), we see a reasonable agreement except over northeastern Canada and Greenland where the model solution shows warming while the observations show cooling. We found that horizontal temperature advection is the primary contributor to the temperature anomalies (not shown). Overall, the model temperature solutions indicate that tropical heating is important for warming the Pacific sector of the Arctic, 


\section{0-hPa streamfunction anomaly in $\mathrm{E}_{\mathrm{T}} \mid \mathrm{T}_{\mathrm{T}}^{+}$subset exp. \\ Model days 10 to 12

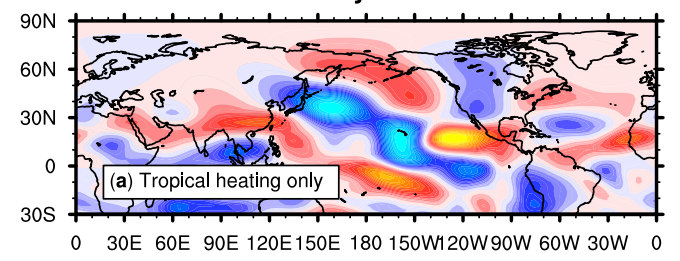

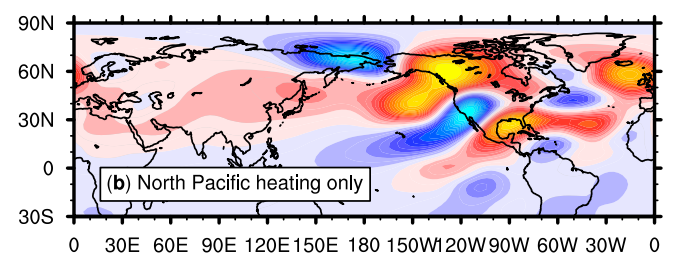
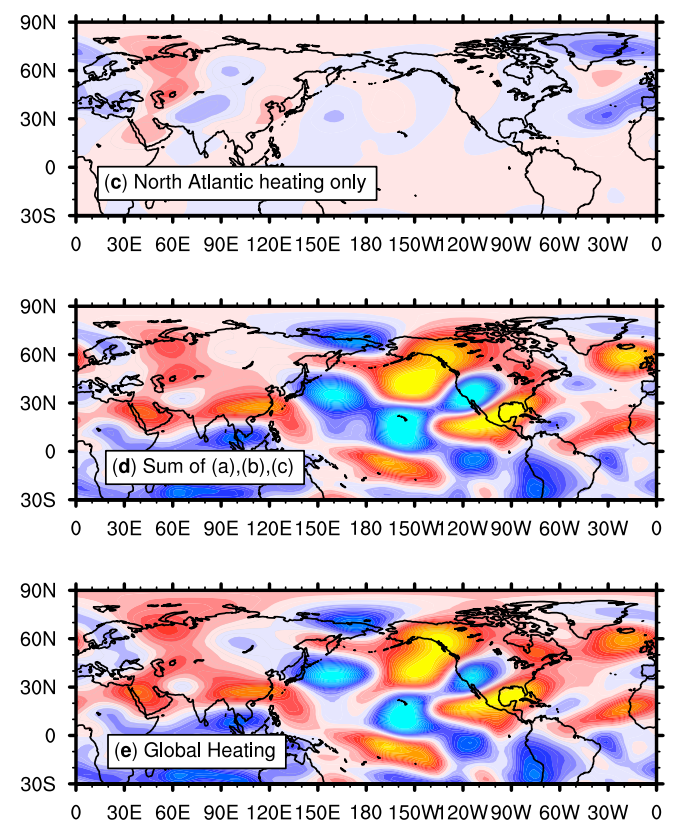

longitude

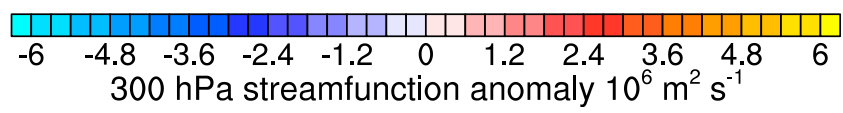

FIG. 6. The 300-hPa streamfunction anomaly averaged from model days 10 to 12 . The model is forced with the heating composite of the $E_{T} \mid \mathcal{T}_{T}^{+}$subset-both tropical and extratropical heating is anomalously large during SWI+ days-for (a) the tropics, (b) the North Pacific domain, (c) the North Atlantic domain, (d) the sum of (a)-(c), and (e) the entire globe.

while extratropical heating is more important for warming the Atlantic sector.

\section{b. Passive tracer response}

We next address the question of whether tropical heating anomalies can lead to the North Pacific and North Atlantic heating anomalies. Figures $8 \mathrm{a}$ and $8 \mathrm{~b}$ show passive tracer fields simulated by the model. The initial condition of the tracer is the three-dimensional climatological specific humidity during boreal winter. During model days 10-12, it can be seen that the circulation driven by tropical heating transports anomalous tracer over the central North Pacific and western North America, as well as over the east coast of North America 
Model temperature anomaly induced by heating in $\mathrm{E}_{\mathrm{T}} \mid \mathrm{T}_{\mathrm{T}}^{+}$

Model Day 11-16
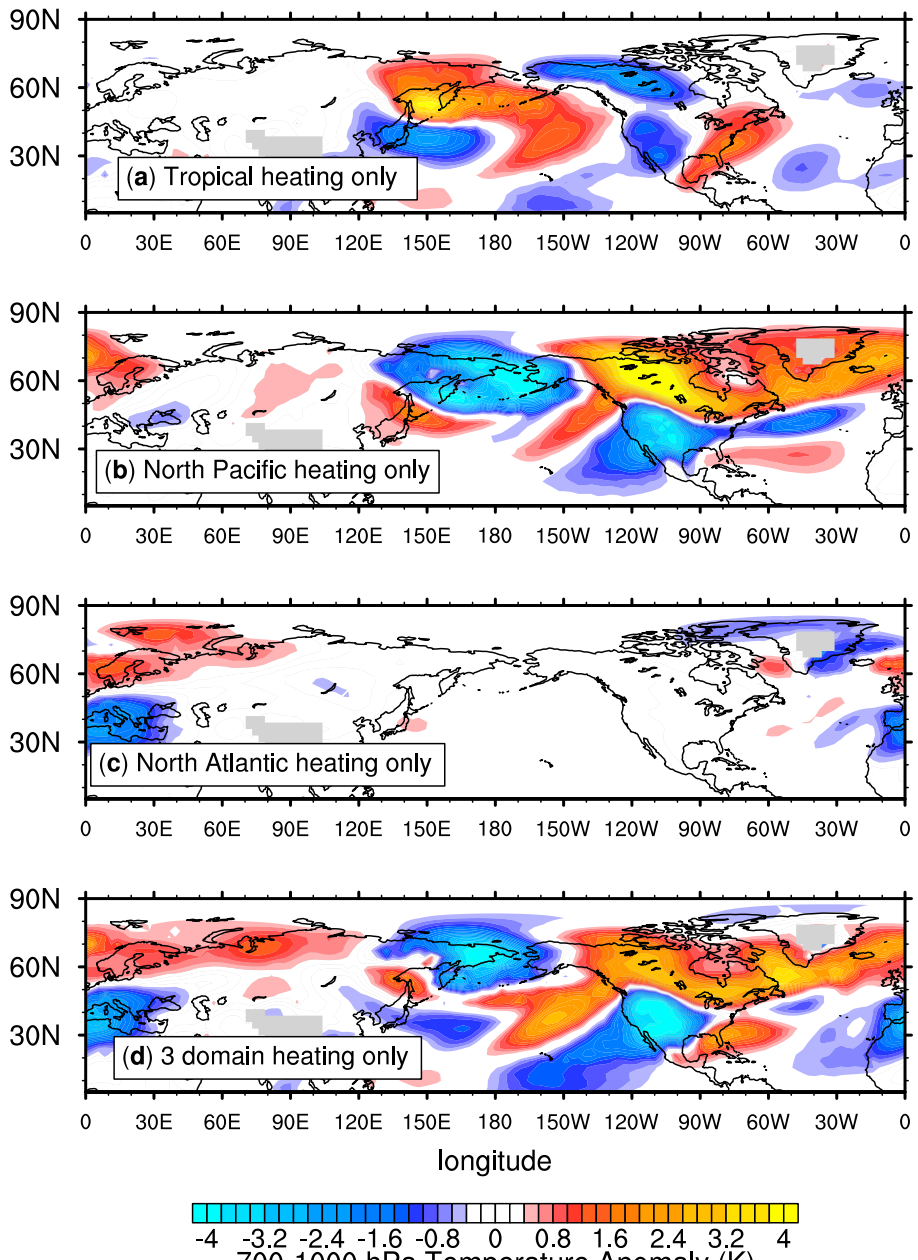

700-1000 hPa Temperature Anomaly (K)

FIG. 7. The lower-tropospheric $(700-1000 \mathrm{hPa})$ temperature anomaly averaged from model days 11 to 16. The same heating composites as in Fig. 6 are used to force the model, but only over (a) the tropical, (b) the North Pacific, and (c) the North Atlantic domain. (d) Summation of (a)-(c). Gray shading denotes the region where surface pressure is below $700 \mathrm{hPa}$.

and the northern subtropical North Atlantic (Fig. 8a). Figure $8 \mathrm{~b}$ shows that North Pacific heating also contributes to the positive tracer anomaly over northwestern North America and the northeastern North Atlantic.

Because this passive tracer transport represents moisture transport, the model condensational heating can be estimated (see appendix for the method). The results (Figs. 8c and 8d) show horizontal structures that resemble the composite heating field (Fig. 3a), supporting that the lead-lag relationships in Fig. 2 are indeed causal. The model result also suggests a positive feedback process where the North Atlantic heating drives a circulation that can reinforce the heating that drove the circulation in the first place. This positive feedback is reminiscent of the mechanism of Hoskins and Valdes (1990), but it differs in the sense that the feedback suggested here is through the interplay between latent heating and circulation while the mechanism of Hoskins and Valdes (1990) is self-maintaining through latent heating, circulation, and baroclinity. When tropical and extratropical heating are imposed together, anomalous tracer transport poleward of $60^{\circ} \mathrm{N}$ is found mostly over the two ocean corridors where anomalous moisture transport into the Arctic Ocean occur (not shown). This result shows that when forced by latent heating, moisture transport, via an 


\section{Model day 10 to 12 (Tropical heating only) Model day 11 to 13 (North Pacific heating only)}
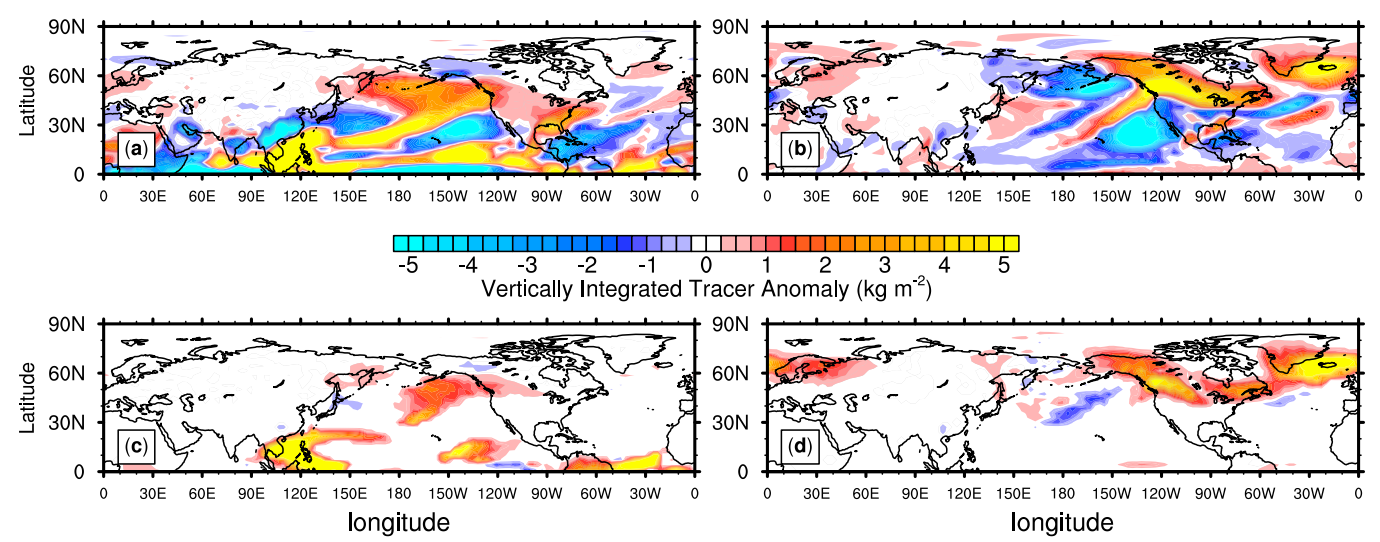

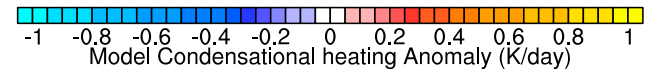

FIG. 8. (a),(b) The vertically integrated tracer anomaly averaged over model days (a) 10-12 and (b) 11-13. The same heating composites as in Fig. 6 are used to force the model, but only over (left) the tropical and (right) the North Pacific domain. (c),(d) The vertically integrated condensational heating computed from the tracer anomalies in (a) and (b), respectively (see section $4 \mathrm{~b}$ and appendix for details).

increase in downward infrared radiation, is likely to reinforce temperature changes caused by dry dynamics (Yoo et al. 2012).

To quantify the tropics-North Pacific-North Atlantic linkage that involves heating and "moisture" transport, we compute area-weighted averages of the net tracer anomaly over the North Pacific and North Atlantic domains forced by tropical, North Pacific, and North Atlantic heating. Figure 9a shows that, for the Pacific domain, tropical heating is the main driver of tracer transport, whereas the net effect of extratropical heating is nearly zero. For the Atlantic domain illustrated in Fig. 9b, the tracer anomaly forced by North Pacific heating is predominant. To further evaluate the resemblance between the model tracer anomaly and the reanalysis heating anomaly, we compute the projection of the condensational heating estimated from tracer anomalies, shown in Figs. 8c and 8d, onto the composites of heating anomalies $\overline{Q_{\mathrm{SWI}}}$ in the same manner as constructing the heating indices. The result again supports the proposed causality.

\section{Summary and conclusions}

In this study, we addressed the following two questions: 1) During SWI events, what circulation and temperature anomalies are induced by the individual heating anomalies over the tropics and extratropics? 2) During SWI events, is there any evidence that extratropical heating is excited by waves forced by tropical heating?
To address the first question, we binned the SWI+ days by ranking the magnitude of tropical and extratropical latent heating. Our analyses reveal that there are different flavors of stationary wave interferences. Simultaneous enhancements in zonal asymmetries in both tropical and extratropical heating $\left(E_{T} \mid \mathcal{T}_{T}^{+}\right)$generate circulation interferences not only in the midlatitudes but also in the Arctic, hence the strongest moisture flux into the Arctic. When the zonal asymmetry in the heating field is suppressed $\left(E_{B} \mid \mathcal{T}_{B}^{+}\right)$, stationary wave interference is mostly confined to midlatitudes, and its impact on Arctic temperature is substantially weaker.

To address the second question, we first examined the lead-lag relationships among the tropical and the two extratropical heating indices. The result indicates that while the latent heating anomalies in these three domains can occur by themselves, they tend to occur together within 7-10 days of each other, with the tropical heating anomaly leading the North Pacific heating anomaly, which in turn is followed by the North Atlantic anomaly. This finding suggests that not only the answer to this second question be positive, but also that the circulation driven by the North Pacific heating enhances latent heating over the North Atlantic domain. We tested this heating-circulation relay hypothesis with the model by computing condensational heating from the model's passive tracer, which represents specific humidity. This initial-value passive tracer experiment indeed supports the heating-circulation relay hypothesis that emerged from the observational analysis: tropical 
Tracer anomaly and estimated heating over North Pacific/Atlantic domain
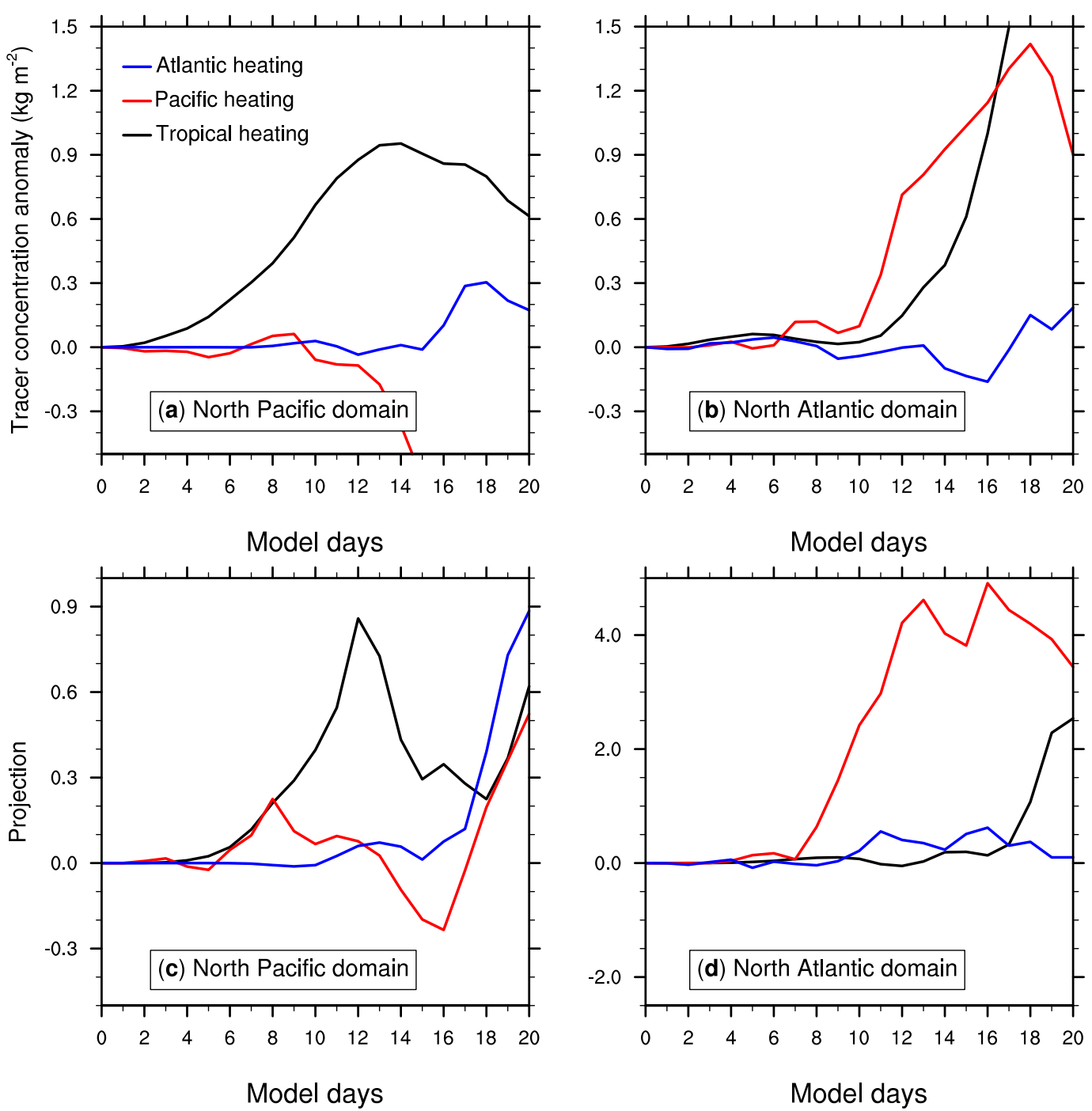

FIG. 9. (a),(b) Time series of the area-weighted average of the vertically integrated tracer anomaly. (c),(d) Time series of projection of the model condensational heating anomaly computed from the model tracer onto the observed latent heating anomaly field in the $E_{T} \mid \mathcal{T}_{T}^{+}$subset where both tropical and extratropical heating are anomalously large during SWI+. The projection domain is the North Pacific for (a) and (c) and the North Atlantic for (b) and (d). The black, red, and blue lines denote the model response to the tropical, North Pacific, and North Atlantic heating composites, respectively.

latent heating $\rightarrow$ circulation anomalies $\rightarrow$ latent heating in the North Pacific $\rightarrow$ circulation anomalies $\rightarrow$ latent heating in the North Atlantic.

The relay picture is a reminder that diabatic heating is not only an important driver of the atmospheric circulation (e.g., Sutcliffe 1951; Hoskins and Valdes 1990), but it also reveals that the extratropical diabatic heating is dependent on tropical heating. The implication is that while the atmospheric response to the individual components of the heating is linear, they are not independent of each other. Therefore, the impact of the tropical heating should not be readily dismissed even for a circulation feature attributable to extratropical heating.

Acknowledgments. We acknowledge discussion with Steven Feldstein and Joseph Clark throughout this study and Steven Feldstein for his comments on this manuscript. We also acknowledge comments by anonymous reviewers. This research is supported by National Science Foundation Grants AGS-1455577, AGS-1822015 and OPP-1723832. 


\section{APPENDIX}

\section{Estimation of Condensational Heating from Model Passive Tracer}

We first compute saturation vapor pressure $e_{s}$ at each grid point using the solution to the Clausius-Clapeyron equation shown by Bohren and Albrecht [1998; their Eq. (5.67)]:

$$
\ln \frac{e_{s}}{e_{s 0}}=6808\left(\frac{1}{T_{0}}-\frac{1}{T}\right)-5.09 \ln \frac{T}{T_{0}},
$$

where $e_{s 0}=6.11 \mathrm{hPa}$ and $T_{0}=273 \mathrm{~K}$. Next, we compute the amount of condensation by assuming that condensation takes place when the relative humidity reaches 100\% (Manabe et al. 1965):

$$
q_{\mathrm{cond}}=\left\{\begin{array}{ccc}
q_{\mathrm{tr}}-w_{s} & \text { if } & r \geq 1 \\
0 & \text { if } & r<1
\end{array},\right.
$$

where $q_{\text {tr }}$ is the tracer in the model and $w_{s}$ is the saturation mixing ratio, which can be computed from the saturation vapor pressure using

$$
w_{s}=\frac{0.622 e_{s}}{p-e_{s}} .
$$

Because specific humidity, which is the tracer in our model, is very small $(\ll 1)$ in the atmosphere, it can be approximated as the mixing ratio. The relative humidity can then be computed using the following relation:

$$
r \approx \frac{w}{w_{s}}=\frac{q_{\mathrm{tr}}}{w_{s}}
$$

With the $q_{\text {cond }}$ obtained from (A1), the corresponding heating rate was computed using the following expression:

$$
Q=\frac{1}{\rho C_{p} D}\left(\frac{1}{g} \int_{P_{1}}^{P_{2}} l_{v} q_{\text {cond }} d p\right),
$$

where $\rho$ is density of air, $C_{p}$ is the specific heat of dry air at constant pressure, $l_{v}$ is the latent heat of vaporization, $g$ is the acceleration of gravity, and $D$ is the vertical depth of the heating, corresponding to pressure level between $P_{2}$ and $P_{1}$. To define the model anomaly, we subtract the heating rate of the control experiment from that of the perturbation experiments.

\section{REFERENCES}

Baggett, C., S. Lee, and S. B. Feldstein, 2016: An investigation of the presence of atmospheric rivers over the North Pacific during planetary-scale wave life cycles and their role in Arctic warming. J. Atmos. Sci., 73, 4329-4347, https://doi.org/10.1175/ JAS-D-16-0033.1.
Bohren, C. F., and B. A. Albrecht, 1998: Atmospheric Thermodynamics. Oxford University Press, 198 pp.

Chang, E. K., 2009: Diabatic and orographic forcing of northern winter stationary waves and storm tracks. J. Climate, 22, 670 688, https://doi.org/10.1175/2008JCLI2403.1.

Dee, D. P., and Coauthors, 2011: The ERA-Interim reanalysis: Configuration and performance of the data assimilation system. Quart. J. Roy. Meteor. Soc., 137, 553-597, https://doi.org/ 10.1002/qj.828.

Feldstein, S. B., 2002: Fundamental mechanisms of the growth and decay of the PNA teleconnection pattern. Quart. J. Roy. Meteor. Soc., 128, 775-796, https://doi.org/10.1256/0035900021643683.

Fletcher, C. G., and P. J. Kushner, 2011: The role of linear interference in the annular mode response to tropical SST forcing. J. Climate, 24, 778-793, https://doi.org/10.1175/2010JCLI3735.1.

Franzke, C., S. Lee, and S. B. Feldstein, 2004: Is the North Atlantic Oscillation a breaking wave? J. Atmos. Sci., 61, 145-160, https:// doi.org/10.1175/1520-0469(2004)061<0145:ITNAOA $>2.0$. CO;2.

Garfinkel, C. I., S. B. Feldstein, D. W. Waugh, C. Yoo, and S. Lee, 2012: Observed connection between stratospheric sudden warmings and the Madden-Julian oscillation. Geophys. Res. Lett., 39, L18807, https://doi.org/10.1029/2012GL053144.

Goss, M., S. B. Feldstein, and S. Lee, 2016: Stationary wave interference and its relation to tropical convection and Arctic warming. J. Climate, 29, 1369-1389, https://doi.org/10.1175/ JCLI-D-15-0267.1.

Held, I. M., and M. J. Suarez, 1994: A proposal for the intercomparison of the dynamical cores of atmospheric general circulation models. Bull. Amer. Meteor. Soc., 75, 1825-1830, https://doi.org/10.1175/ 1520-0477(1994)075<1825:APFTIO > 2.0.CO;2.

_ M. Ting, and H. Wang, 2002: Northern winter stationary waves: Theory and modeling. J. Climate, 15, 2125-2144, https://doi.org/ 10.1175/1520-0442(2002)015<2125:NWSWTA > 2.0.CO;2.

Hoskins, B. J., and D. J. Karoly, 1981: The steady linear response of a spherical atmosphere to thermal and orographic forcing. J. Atmos. Sci., 38, 1179-1196, https://doi.org/10.1175/15200469(1981)038<1179:TSLROA > 2.0.CO;2.

- and P. J. Valdes, 1990: On the existence of storm-tracks. J. Atmos. Sci., 47, 1854-1864, https://doi.org/10.1175/15200469(1990)047<1854:OTEOST>2.0.CO;2.

Kobayashi, S., and Coauthors, 2015: The JRA-55 Reanalysis: General specifications and basic characteristics. J. Meteor. Soc. Japan, 93, 5-48, https://doi.org/10.2151/jmsj.2015-001.

Lee, S., 2012: Testing of the tropically excited Arctic warming mechanism (TEAM) with traditional El Niño and La Niña. J. Climate, 25, 4015-4022, https://doi.org/10.1175/JCLI-D-12-00055.1.

_ 2014: A theory for polar amplification from a general circulation perspective. Asia-Pac. J. Atmos. Sci., 50, 31-43, https:// doi.org/10.1007/s13143-014-0024-7.

Ling, J., and C. Zhang, 2013: Diabatic heating profiles in recent global reanalyses. J. Climate, 26, 3307-3325, https://doi.org/ 10.1175/JCLI-D-12-00384.1.

Lorenz, E. N., 1955: Available potential energy and the maintenance of the general circulation. Tellus, 7, 157-167, https:// doi.org/10.3402/tellusa.v7i2.8796.

Madden, R. A., and P. R. Julian, 1971: Detection of a 40-50 day oscillation in the zonal wind in the tropical Pacific. J. Atmos. Sci., 28, 702-708, https://doi.org/10.1175/1520-0469(1971)028<0702: DOADOI $>2.0 . \mathrm{CO} ; 2$.

Manabe, S., J. Smagorinsky, and R. F. Strickler, 1965: Simulated climatology of a general circulation model with a hydrological cycle. Mon. Wea. Rev., 93, 769-798, https://doi.org/10.1175/ 1520-0493(1965)093<0769:SCOAGC > 2.3.CO;2. 
Ming, Y., and I. M. Held, 2018: Modeling water vapor and clouds as passive tracers in an idealized GCM. J. Climate, 31, 775-786, https://doi.org/10.1175/JCLI-D-16-0812.1.

Overland, J., K. Wood, and M. Wang, 2011: Warm Arctic-cold continents: Climate impacts of the newly open Arctic sea. Polar Res., 30, 15787, https://doi.org/10.3402/polar.v30i0.15787.

Papritz, L., and T. Spengler, 2015: Analysis of the slope of isentropic surfaces and its tendencies over the North Atlantic. Quart. J. Roy. Meteor. Soc., 141, 3226-3238, https://doi.org/10.1002/qj.2605.

Peixoto, J. P., and A. H. Oort, 1992: Physics of Climate. American Institute of Physics, 520 pp.

Pierrehumbert, R. T., H. Brogniez, and R. Roca, 2007: On the relative humidity of the atmosphere. The Global Circulation of the Atmosphere, T. Schneider and A. H. Sobel, Eds., Princeton University Press, 143-185.

Smith, K. L., P. J. Kushner, and J. Cohen, 2011: The role of linear interference in northern annular mode variability associated with Eurasian snow cover extent. J. Climate, 24, 6185-6202, https://doi.org/10.1175/JCLI-D-11-00055.1.

Sutcliffe, R. C., 1951: Mean upper contour patterns of the Northern Hemisphere-The thermal-synoptic view pattern. Quart. J. Roy. Meteor. Soc., 77, 435-440, https://doi.org/10.1002/qj.49707733309.

Ting, M., 1996: Steady linear response to tropical heating in barotropic and baroclinic models. J. Atmos. Sci., 53, 1698-1709, https://doi.org/10.1175/1520-0469(1996)053<1698: SLRTTH $>2.0 . \mathrm{CO} ; 2$.

, and I. M. Held, 1990: The stationary wave response to a tropical SST anomaly in an idealized GCM. J. Atmos. Sci., 47,
2546-2566, https://doi.org/10.1175/1520-0469(1990)047<2546: TSWRTA $>2.0 . \mathrm{CO} ; 2$.

Wheeler, M. C., and H. H. Hendon, 2004: An all-season real-time multivariate MJO index: Development of an index for monitoring and prediction. Mon. Wea. Rev., 132, 1917-1932, https://doi.org/ 10.1175/1520-0493(2004)132<1917:AARMMI>2.0.CO;2.

Willison, J., W. A. Robinson, and G. M. Lackmann, 2013: The importance of resolving mesoscale latent heating in the North Atlantic storm track. J. Atmos. Sci., 70, 2234-2250, https:// doi.org/10.1175/JAS-D-12-0226.1.

Woods, C., and R. Caballero, 2016: The role of moist intrusions in winter Arctic warming and sea ice decline. J. Climate, 29, 4473-4485, https://doi.org/10.1175/JCLI-D-15-0773.1.

, — - and G. Svensson, 2013: Large-scale circulation associated with moisture intrusions into the Arctic during winter. Geophys. Res. Lett., 40, 4717-4721, https://doi.org/10.1002/ grl.50912.

Wright, J. S., and S. Fueglistaler, 2013: Large differences in reanalyses of diabatic heating in the tropical upper troposphere and lower stratosphere. Atmos. Chem. Phys., 13, 9565-9576, https://doi.org/10.5194/acp-13-9565-2013.

Yoo, C., S. Lee, and S. B. Feldstein, 2012: Arctic response to an MJO-like tropical heating in an idealized GCM. J. Atmos. Sci., 69, 2379-2393, https://doi.org/10.1175/JAS-D-11-0261.1.

Zhang, K., W. J. Randel, and R. Fu, 2017: Relationships between outgoing longwave radiation and diabatic heating in reanalyses. Climate Dyn., 49, 2911-2929, https://doi.org/10.1007/ s00382-016-3501-0. 